\title{
PENERAPAN TERAPI MUSIK TERHADAP NYERI NEUROPATI PADA PENYANDANG DIABETES MELLITUS
}

\author{
Jeanny Rantung \\ Faculty of Nursing, Universitas Advent Indonesia, Jl. Kolonel Masturi No 288 Parongpong, 40067 Indonesia \\ E-mail: jeannyrantung@unai.edu
}

\begin{abstract}
Neuropathic pain is one of the chronic complications of Diabetes Mellitus that causes physical, social and spiritual disorders. Music therapy is one of the efforts that nurses can provide to control pain in addition to the pharmacological therapy provided by the medical team. Objective: To investigate the effect of music therpy on pain intensity in patients with neuropathic pain.. Method: The study was quasi experiment with pretest-posttest with control group approach, 10 respondents involved who were divided into music therapy intervention group and control group, which were obtained by accidental sampling technigue. Pain intensity was measured using the Visual Analogue Scale (VAS) which was performed before music therapy was given, in the 30th minute and 60th minute. Results: Respondent who received music therapy experienced a decrease in pain intensity, from moderate to mild pain, and the control group experienced a decrease in pain intensity but still in the moderate pain category. One way ANOVA showed that there were significant reduction in pain intensity after music therapy intervention ( $p<0.05$ ). Conclusion: Music therapy is a nursing intervention that can be an option of therapy or treatment for neuropathic pain..
\end{abstract}

Key words: Music therapy, Neuropathy, Pain

\begin{abstract}
Abstrak
Nyeri neuropati salah satu komplikasi kronik yang dapat dialami penyandang diabetes melitus yang dapat menyebabkan gangguan fisik, sosial dan spiritual. Terapi musik adalah salah satu upaya yang dapat diberikan perawat untuk mengontrol nyeri selain terapi farmakologis yang diberikan oleh tim medis. Tujuan: Penelitian dilakukan ini untuk melihat pengaruh terapi musik terhadap intensitas nyeri neuropati. Metode: Desain penelitian ini adalah kuasi eksperimen dengan pendekatan pretest-posttest with control group, melibatkan 10 orang responden yang dibagi menjadi kelompok intervensi terapi musik dan kelompok kontrol, yang diperoleh melalui teknik accidental sampling. Intensitas nyeri diukur dengan menggunakan Visual Analogue Scale (VAS) yang dilakukan sebelum terapi musik diberikan, pada menit ke-30 dan menit ke-60. Hasil: Responden yang mendapat terapi musik mengalami penurunan intensitas nyeri, dari nyeri sedang menjadi nyeri ringan, dan pada kelompok kontrol mengalami penurunan intensitas nyeri tapi masih dalam kategori nyeri sedang. Uji one way ANOVA menunjukkan penurunan intensitas nyeri yang signifikan setelah pemberian terapi musik $(\mathrm{p}<0.05)$. Kesimpulan: Terapi musik merupaka intervensi keperawatan yang dapat menjadi pilihan terapi untuk mengurangi nyeri neuopati.
\end{abstract}

Kata kunci: Neuropati, Nyeri, Terapi Musik 


\section{Pendahuluan}

Neuropati pada diabetes mengacu pada sekelompok penyakit yang menyerang semua tipe saraf, termasuk saraf perifer (sensori motor), otonom dan spinal (Black \& Hawks, 2009; Smeltzer \& Bare, 2010). Prevalensi neuropati meningkat bersamaan dengan pertambahan usia penderita dan lamanya penyakit, angka prevalensi dapat mencapai $50 \%$ pada pasien-pasien yang sudah menderita diabetes selama 25 tahun. Peningkatan kadar glukosa darah selama bertahuntahun telah membawa implikasi pada etiologi neuropati (Lewis, Dirksen, Heitkemper, Bucher \& Camera, 2011; Smeltzer \& Bare, 2010).

Nyeri neuropati menurut Merskey dan Bogduk (1994) adalah nyeri yang disebabkan oleh kerusakan atau penyakit pada sistem saraf somatosensori. Nyeri neuropatik adalah deksriptif klinis yang menunjukkan adanya kerusakan atau penyakit yang memenuhi kriteria diagnostik neurologis dan proyeksi nyeri pada area persarafan. Penyandang diabetes melitus dapat mengalami nyeri neuropati selain penyakit stroke, vaskulitis, atau kelainan genetik lainnya.

Nyeri neuropati adalah fenomena yang kompleks termasuk keadaan yang serius, termasuk dalam nyeri berat. Area yang paling umum mengalami nyeri neuropati adalah saraf periperal, pleksus, ganglion dorsal, saraf tulang belakang dan otak. Meskipun mekanismenya tidak sepenuhnya dapat dimengerti, nyeri neuropati adalah nyeri yang kompleks dan multifokal dengan keparahan yang meningkat dari waktu ke waktu. Nyeri menyebabkan peningkatan kelelahan serta gangguan aktivitas sehari-hari dalam pekerjaan dan interaksi sosial. Dampak selanjutnya dari situasi ini akan menyebabkan kehilangan pekerjaan yang akan mempengaruhi pasien begitu juga anggota keluarga, keadaan ini menyebabkan munculnya masalah psikologis dan status kesejahteraan sosial. Rasa nyeri yang dirasakan pasien dapat menyebabkan kualitas hidup menurun dan berdampak pada gangguan pemenuhan kebutuhan fisik, spiritual dan sosial. Sehingga menjadi hal yang penting untuk dapat mengendalikan rasa sakit, meringankan rasa sakit, yang akan meningkatkan kualitas hidup, mengurangi komplikasi dan mengurangi lama rawat inap. Keadaan tersebut menjadi alasan untuk mencari pilihan lain selain pilihan manajemen farmakologis (Korhan, et al, 2013; Demir 2012).

Manajemen nonfarmakologis menjadi pilihan pengobatan untuk melengkapi upaya medis yang sudah dilakukan. Penerapan manajemen nonfarmakologis berguna untuk meningkatkan kontrol perasaan individu, mengurangi perasaan lemah, meningkatkan aktivitas dan kapasitas fungsional. Selain itu untuk mengurangi stres dan cemas, mengurangi perilaku nyeri dan tingkat nyeri terfokus, mengurangi dosis analgetik yang dibutuhkan sehingga mengurangi efek samping obat (Demir, 2012).

Metode nonfarmakologis yang digunakan dalam manajemen nyeri 
dapat diklasifikasikan dalam berbagai cara, yaitu kognitif, metode perilaku, atau metode komplementer. Terapi musik merupakan salah satu metode pengobatan kognitif-perilaku yang dapat digunakan sebagai metode untuk mengontrol rasa sakit. Musik telah menjadi bagian penting dari pengaturan medis selama beberapa dekade terakhir, terapi musik merupakan cabang dari perawatan kesehatan yang digunakan untuk perbaikan emosional, fisik, fungsional dan pendidikan dalam berbagai kondisi. Musik telah terbukti memiliki efek fisiologis dan psikologis yang positif pada pasien. Selama ribuan tahun, terapi musik telah digunakan untuk mengurangi rasa sakit dan rasa tidak nyaman (Korhan, et al, 2013)

Sebuah penelitian yang dilakukan di Turki oleh Korhan, et al (2013) terhadap 30 pasien dengan nyeri neuropati berusia 18-70 tahun, responden mendapatkan terapi musik selama 60 menit. Hasil yang ditemukan dalam penelitian itu, rerata intensitas skala nyeri sebelum dan sesudah mengalami penurunan. Intensitas nyeri diukur dengan menggunakan Visual Analog Scale (VAS).

Penelitian lain yang dilakukan di Taiwan terhadap 126 pasien yang mengalami nyeri kanker. Partisipan dipilih secara acak dan dibagi menjadi dua kelompok, yaitu kelompok intervensi sebanyak 62 pasien dan sebanyak 64 pasien menjadi kelompok kontrol. Musik yang dipilih termasuk musik folk, himne Buddha (musik Taiwan), harpa dan piano (Amerika). Hasilnya menunjukkan nyeri berkurang secara signifikan setelah intervensi ( $\mathrm{p}<.001)$ (Huang, Good, \& Zauszniewski, 2010).

Meskipun demikian, manajemen nyeri neuropati lebih banyak menggunakan terapi farmakologi dibandingkan dengan terapi nonfarmakologi.sehingga perawat cenderung melaksanakan program terapi kolaborasi dengan dokter yaitu pemberian terapi farmakologis. Masih banyak perawat bergantung pada terapi medis, karena ragu, tidak percaya diri atau terlalu sibuk sehingga tidak melaksanakan intervensi mandiri keperawatan. padahal intervensi musik adalah intervensi keperawatan yang memfasilitasi penyembuhan pasien.

Berdasaran data-data di atas dan penelitian sebelumnya, maka tujuan penelitian ini adalah untuk melihat pengaruh terapi musik terhadap nyeri neuropati pada penyandang Diabetes Mellitus (DM).

\section{Metode}

Penelitian ini adalah quasi experiment dengan pretest posttest with control design. Penetapan subyek ditentukan berdasarkan accidental sampling, dilakukan pada bulan Nopember 2013, melibatkan pasien DM yang dirawat di sebuah RSU Jakarta yang terdiri dari kelompok intervensi sebanyak 5 orang dan kelompok kontrol sebanyak 5 orang. Kriteria inklusi subjek adalah: pasien DM tipe 2, mengalami nyeri neuropati, setuju terlibat dalam penelitian, memiliki pendengaran yang baik, tidak sedang menggunakan terapi analgetik. Kriteria eksklusi adalah menderita kelainan psikiatrik, minum 
obat tidur atau obat sedatif lainnya, pernah menerima metode pengobatan alternative atau komplimentari sebelumnya.

Skrining nyeri neuropati dilakukan dengan menggunakan Douleur Neuropathique 4 questionnaire (DN4) yang dikembangkan oleh Bouhassira et al (2005), untuk versi bahasa Indonesia sudah dilakukan uji validitas dan reabilitas modifikasi oleh Lestari, Widyadharma dan Merati (2013) dengan hasil konsistensi internal berkisar $0.70-0.92$ dan nilai reabilitas alpha cronbach 0.86 . Pengkajian nyeri neuropati, melalui pemeriksaan sensasi rasa menggunakan monofilament 10 gr 5.07, dan menilai intensitas nyeri dengan menggunakan VAS. Untuk mengolah data statistik perbedaan intensitas nyeri menggunakan uji hipotesis one way ANOVA.

\section{Hasil Penelitian}

Tabel 1 menggambarkan hasil penelitian menunjukkan sebagian besar responden berjenis kelamin perempuan yaitu sebanyak 7 orang (70\%) dan laki-laki 3 orang (30).

Tabel 1. Data Demografi Responden Berdasarkan Jenis Kelamin ( $\mathrm{N}=10$ orang)

\begin{tabular}{lcc}
\hline \multicolumn{1}{c}{ Variabel } & Frekwensi & Persentase \\
\hline Jenis & & \\
Kelamin & & \\
Laki-laki & 3 & 30 \\
Perempuan & 7 & 70 \\
\hline
\end{tabular}

Tabel 2 menunjukkan responden ratarata berusia 50.7 tahun dengan rentang usia 45 - 60, lama menderita DM rata- rata 4.5 tahun dengan rentang $1-7$ tahun, dan kadar HBA1c rata-rata 6.7 dengan nilai terendah 6.1 dan tertinggi 6.9

Tabel 2. Distribusi Responden berdasarkan Usia, Lama Menderita DM, Kadar HBA1c ( $\mathrm{N}=10$ orang)

\begin{tabular}{lcccl}
\hline Variabel & Mean & Med & SD & $\begin{array}{l}\text { Min- } \\
\text { Maks }\end{array}$ \\
\hline Usia & 50.7 & 49.5 & 5.06 & $45-60$ \\
$\begin{array}{l}\text { Lama } \\
\text { Menderita }\end{array}$ & 4.5 & 5.50 & 2.27 & $1-7$ \\
DM & & & & \\
$\begin{array}{l}\text { Kadar } \\
\text { HBA1c }\end{array}$ & 6.7 & 6.8 & .296 & $6.1-6.9$ \\
\hline
\end{tabular}

Intensitas nyeri pada kelompok intervensi dapat diliht pada Tabel 3, dimana intensitas nyeri rata-rata mengalami penurunan, pada menit ke30 setelah pemberian terapi musik intensitas nyeri dari $58.4 \mathrm{~mm}$ (nyeri sedang) menjadi $45.6 \mathrm{~mm}$ (nversi Indonesia yeri sedang) dan pada menit ke-60 menjadi $29.6 \mathrm{~mm}$ (nyeri ringan). Dapat disimpulkan responden yang mendapat terapi musik mengalami penurunan intensitas nyeri, dari nyeri sedang menjadi nyeri

Tabel 3. Distribusi Responden Terhadap Nyeri Setelah Intervensi Terapi Musik

\begin{tabular}{lcccccc}
\hline & 1 & 2 & 3 & 4 & 5 & $\begin{array}{c}\text { Rata- } \\
\text { Rata }\end{array}$ \\
\hline $\begin{array}{l}\text { menit } \\
\text { mm }\end{array}$ & $\begin{array}{c}57 \\
\mathrm{~mm}\end{array}$ & $\begin{array}{c}68 \\
\mathrm{~mm}\end{array}$ & $\begin{array}{c}47 \\
\mathrm{~mm}\end{array}$ & $\begin{array}{c}60 \\
\mathrm{~mm}\end{array}$ & $\begin{array}{c}58.4 \\
\mathrm{~mm}\end{array}$ \\
\hline $\begin{array}{l}30 \\
\text { menit }\end{array}$ & $\begin{array}{c}45 \\
\mathrm{~mm}\end{array}$ & $\begin{array}{c}43 \\
\mathrm{~mm}\end{array}$ & $\begin{array}{c}55 \\
\mathrm{~mm}\end{array}$ & $\begin{array}{c}35 \\
\mathrm{~mm}\end{array}$ & $\begin{array}{c}50 \\
\mathrm{~mm}\end{array}$ & $\begin{array}{c}45.6 \\
\mathrm{~mm}\end{array}$ \\
\hline $\begin{array}{l}60 \\
\text { menit }\end{array}$ & $\begin{array}{c}25 \\
\mathrm{~mm}\end{array}$ & $\begin{array}{c}30 \\
\mathrm{~mm}\end{array}$ & $\begin{array}{c}40 \\
\mathrm{~mm}\end{array}$ & $\begin{array}{c}18 \\
\mathrm{~mm}\end{array}$ & $\begin{array}{c}35 \\
\mathrm{~mm}\end{array}$ & $\begin{array}{c}29.6 \\
\mathrm{~mm}\end{array}$ \\
\hline
\end{tabular}


Intensitas nyeri pada kelompok kontrol dapat dilihat pada tabel 4, dimana intesitas nyeri $64 \mathrm{~mm}$ (nyeri sedang) menjadi $58.2 \mathrm{~mm}$ (nyeri sedang) pada menit ke-30, dan pada menit ke-60 intensitas nyeri 54.6 (nyeri sedang). Disimpulkan bahwa meskipun intensitas nyeri pada kelompok kontrol mengalami penurunan intensitas nyeri tapi masih dalam kategori nyeri sedang.

Tabel 4. Distribusi Responden Terhadap Nyeri Pada Kelompok Kontrol

\begin{tabular}{lcccccc}
\hline & 1 & 2 & 3 & 4 & 5 & $\begin{array}{c}\text { Rata- } \\
\text { Rata }\end{array}$ \\
\hline $\begin{array}{l}\text { menit } \\
\mathrm{mm}\end{array}$ & $\begin{array}{c}69 \\
\mathrm{~mm}\end{array}$ & $\begin{array}{c}73 \\
\mathrm{~mm}\end{array}$ & $\begin{array}{c}52 \\
\mathrm{~mm}\end{array}$ & $\begin{array}{c}60 \\
\mathrm{~mm}\end{array}$ & $\begin{array}{c}64 \\
\mathrm{~mm}\end{array}$ \\
\hline $\begin{array}{l}30 \\
\text { menit }\end{array}$ & $\begin{array}{c}60 \\
\mathrm{~mm}\end{array}$ & $\begin{array}{c}61 \\
\mathrm{~mm}\end{array}$ & $\begin{array}{c}70 \\
\mathrm{~mm}\end{array}$ & $\begin{array}{c}46 \\
\mathrm{~mm}\end{array}$ & $\begin{array}{c}54 \\
\mathrm{~mm}\end{array}$ & $\begin{array}{c}58.2 \\
\mathrm{~mm}\end{array}$ \\
\hline $\begin{array}{l}60 \\
\text { menit }\end{array}$ & $\begin{array}{c}55 \\
\mathrm{~mm}\end{array}$ & $\begin{array}{c}61 \\
\mathrm{~mm}\end{array}$ & $\begin{array}{c}65 \\
\mathrm{~mm}\end{array}$ & $\begin{array}{c}42 \\
\mathrm{~mm}\end{array}$ & $\begin{array}{c}50 \\
\mathrm{~mm}\end{array}$ & $\begin{array}{c}54.6 \\
\mathrm{~mm}\end{array}$ \\
\hline
\end{tabular}

Pada kelompok intervensi menunjukkan nilai $\mathrm{p}=.000$ ( $\mathrm{p}$ value < 0.05), hal ini menggambarkan terdapat perbedaan intensitas nyeri yang signifikan setelah pemberian terapi musik. Pada kelompok kontrol didapatkan nilai $\mathrm{p}=.268$ ( $\mathrm{p}$ value > 0.05), menunjukkan tidak terdapat perbedaan yang signifikan terhadap penurunan intensitas nyeri (Tabel 5).

Tabel 5. Uji ANOVA

\begin{tabular}{lccc}
\hline & df & F & Sig. \\
\hline Intervensi & & & \\
Between & 2 & 16.666 & .000 \\
Groups & & & \\
Within & 12 & & \\
Groups & & & \\
\hline
\end{tabular}

\begin{tabular}{lccc}
\hline Total & 14 & & \\
\hline Kontrol & & & \\
Between & 2 & 1.473 & .268 \\
Groups & & & \\
Within & 12 & & \\
Groups & & & \\
Total & 14 & & \\
\hline
\end{tabular}

\section{Pembahasan}

Nyeri neuropati sulit untuk diobati secara tehnik medis. Pengobatan nyeri neuropatik diarahkan pada gejala dan temuan serta mekanisme yang menyebabkan terjadinya neuropati. Metoda nonfarmakologi menjadi salah satu pilihan yang dapat membantu mengatasi nyeri neuropati. Terapi musik merupakan intervensi dengan biaya murah, dengan resiko yang rendah, mudah untuk diterapkan. Musik secara spesifik digunakan sebagai terapi intervensi sejak pertengahan abad ke-20. Beberapa tahun terakhir, semakin meningkat penggunaan terapi musik sebagai intervensi, sebagai refleksi meningkatnya minat terhadap terapi komplimenter (Korhan, et al, 2013).

Hasil penelitian menunjukkan terapi musik sebagai intervensi nonfarmakologi keperawatan untuk mengatasi nyeri. Ditemukan pasien mengalami penurunan intensitas nyeri, dari nyeri sedang menjadi nyeri ringan. Hasil uji ANOVA didapatkan $\mathrm{p}$ value .000 ( $\mathrm{p}$ value <0.05) maka dapat disimpulkan ada pengaruh terapi musik terhadap penurunan intensitas nyeri. Sejalan dengan penelitian yang dilakukan oleh Hooks (2014) pada 60 orang pasien paska replacement lutut dibagi menjadi kelompok intervensi musik klasik dan kontrol. Hasil uji statistik menunjukkan ada pengaruh 
yang signifikan terhadap intensitas nyeri pada kelompok intervensi terapi musik ( $\mathrm{F}=.298 ; \mathrm{p}=.037)$. Penelitian lain yang sama dimana terjadi penurunan intensitas nyeri pada pasien paska replacement lutut, paska operasi dan paska operasi pada pasien ortopedik sebagai respon terhadap intervensi terapi musik (Hooks, 2014; Radcliffe \& Porterfield, 2018; Schneider, 2018). Penelitian yang dilakukan oleh Lee (2016) mendapatkan hasil penurunan secara signifikan terhadap penggunaan medikasi.

Menurut Demir (2012), pengaruh terapi musik pada nyeri adalah dengan distraksi pikiran terhadap nyeri, menurunkan kecemasan dan ketegangan tubuh, mengatur ritme napas lebih teratur, relaksasi, serta meningkatkan mood yang positif. Selanjutnya, terapi musik membantu mengurangi stres, ketakutan, kecemasan, depresi, serta insomnia.

Otak memproses musik dan nyeri di sepanjang jalur saraf yang sama, untuk menjelaskan fenomena ini dapat dijelaskan melalui teori Gate Control dimana sinyal nyeri yang dikirim melalui reseptor saraf di sumsum tulang belakang menstimulasi sinapsis untuk menyampaikan informasi ke otak. Sinapis diyakini bertindak sebagai gerbang yang membuka dan menutup dalam menanggapi impuls nyeri. Ketika gerbang ditutup, maka sinyal akan dihambat menuju ke otak. Namun, ketika gerbang terbuka, impuls dapat melakukan perjalanan menuju otak, sehingga menyadari rasa nyeri. Musik diyakini mengirim input sensori melalui jalur dari otak sehingga menyebabkan batang otak mengelurakan sinyal untuk menutup gerbang sehingga mengurangi rasa nyeri saat mendengar musik (Economidou et al, 2012). Musik tidak hanya menghambat otak untuk menerima sinyal nyeri, tetapi juga menyebabkan tubuh melepaskan endorphin melalui proses modulasi otonom. Neurotransmiter di otak akan dilepaskan ketika ada impuls musik, yang akan merangsang sistem biologis lain, seperti kelenjar endokrin yang melepaskan endorphin. Hambatan terhadap respon nyeri dan merangsang pelepasan opiod endogen tubuh. Musik juga bekerja pada sistem limbik yang akan diantar menuju sistem saraf. Mengatur kontraksi otot-otot sehingga kontraksi otot berkurang (Lin, et al, 2011; Potter \& Perry, 2011).

Penelitian ini dilakukan dengan mengukur intensitas nyeri sebelum terapi musik, kemudian diukur pada menit ke-30 dan menit ke-60. Hasil menunjukkan intensitas nyeri mengalami penurunan, setelah intervensi terapi musik intensitas nyeri pada kategori nyeri sedang menjadi nyeri ringan hal ini menunjukkan tren penurunan intensitas nyeri dimulai pada menit ke-30. Penelitian yang dilakukan oleh Guetin et al (2012) dengan memberikan intervensi musik selama 20 menit, dua kali sehari selama 3 bulan, dalam keadaan rileks, menggunakan earphone di terapkan saat di rumah sakit dan saat mereka di rumah, menunjukkan hasil penurunan nyeri yang signifikan. Penelitian lain dilakukan oleh Onieva-Zavra, Casto Sanchez, Mataran-Penarrocha dan Moreno-Lorenzo (2013) intervensi musik diberikan selama 60 menit 
setiap hari untuk 4 minggu berturutturut, mengalami penurunan nyeri secara signifikan.

Usia, jenis kelamin dan pendidikan tidak memberikan pengaruh pada skor nyeri (Ozer, Karaman Ozlu, Arslan, Gunes, 2010; Onieva-Zavra, Casto Sanchez, Mataran-Penarrocha, Moreno-Lorenzo, 2013).

Keterbatasan penelitian ini adalah intervensi terapi musik tidak diberikan dalam waktu yang sama pada setiap responden sehingga dapat mempengaruhi skor nyeri yang dikumpulkan. Jumlah responden yang terlibat hanya sedikit karena sulit untuk memenuhi kriteria inklusi (nyeri neuropati).

\section{Kesimpulan}

Intervensi terapi musik terhadap nyeri neuropati diabetes merupakan tindakan non farmakologi, non inpasif, tidak mahal dan intervensi keperawatan yang dapat dilakukan dengan mudah bagi pasien. Pelaksanaan intervensi terapi musik melibatkan perawat dalam memberikan asuhan keperawatan yang komprehensif kepada pasien diabetes dengan nyeri neuropati. Selain perawat, tim kesehatan lain seperti dokter juga bertanggung jawab dalam melakukan pengkajian yang lebih teliti dan cermat khususnya terhadap nyeri neuropati diabetes, yang sering tidak terkaji saat pengkajian awal dilakukan. Penatalaksanaan terapi musik merupakan intervensi keperawatan yang dapat menjadi pilihan terapi atau pengobatan terhadap nyeri neuropati diabetes sehingga menjadi pelengkap terhadap upaya medis yang sudah dilakukan. Hasil pengkajian yang teliti dan cermat saat pasien masuk di ruang rawat akan mengurangi stres dan rasa cemas pasien, mengurangi nyeri sehingga tingka nyeri terfokus, serta mengurangi dosis analgetik yang dapat mengurangi efek samping obat. Intervensi musik merupakan intervensi keperawatan sehingga perawat berperan dalam melaksanakannya.

Rekomendasi yang dapat diberikan adalah melakukan penelitian selanjutnya melibatkan responden yang lebih banyak dan dalam waktu yang panjang dengan intervensi terapi musik diberikan dalam waktu yang sama pada setiap responden .

\section{Daftar Pustaka}

Black, J.M., \& Hawks, J.H. (2009). Medical Surgical Nursing Clinical Management For Positive Outcomes. $8^{\text {th }}$ edition. St. Louis : Saunders Elsevier

Bouhassira D, Attal N, Alchaar H, Boureau F, Brochet B, Bruxelle J, et al. (2005). Comparison Of Pain Syndromes Associated with Nervous Or Somatic Lesions And Development Of A New Neuropathic Pain Diagnostic Questionnaire (DN4). Pain 14, 29-36. www.AAFPLearninglink.org

Demir, Y. (2012). Non-Pharmacological Therapies In Pain Management.-Current. Issues And Opinions. Croacia : Intech. http://cdn.intechopen.com/pdfs/26152/InT echNon_pharmacological_therapies_in_p ain_management.pdf

Economidou, E., Klimi, A., Vivilaki, V.G., \& Lykeridou, K. (2012). Does Music Reduce Postoperative Pain? A Review. Health Sicince Journal. 6 (3) 365 - 377. 
Guetin S., Ginies, P., Siou, D., Picot, M.C., Pommie, C., Guldner, E...Touchon, J. (2012). The effects of music intervention $\mathrm{n}$ the management of chronic pain. Clin $j$ pain. 28: 329 - 337

Hooks, H.E. (2014). Effect of Music Intervention on the patient's perception of pain after knee replacement. Electronic Thesis and Dissertations. Paper 2321. Diperoleh dari http://dc.estu.edu/etd/2321

Huang, S.T., Good, M., \& Zauszniewski. (2010). The effectiveness of music in relieving pain in cancer patients: A randomized controlled trial. International Journal of Nursing Studies, 47 (11), 1354-1362

Korhan, E.A; Uyar, M; Eyigor, C; Yont, G.H; Celik, S \& Korshid, L. (2013). The effects of music therapy on pain in patients with neuropathic pain. American Society for Pain Management Nursing, 02 (12), 1-9

Lee, J.H. (2016). The effects of music on pain: a meta-analysis. Journal of Music Therapy. 53(4), 430-477

Lesatari, T., Widyadharma, E., \& Merati, T.P. (2013). Uji reliabilitas dan validitas modifikasi neuropathic pain diagnostic questionnaire (DN4) terhadap leeds assesment neuropathic symptoms and sign (LANSS) pada pasien HIV/AIDS. Diperoleh dari http://www.researchgate.net/publication/2 76060724

Lewis, S. L., Dirksen, S.R., Heitkemper, M.M.,

Bucher, L., \& Camera, I.M. (2011). Medical surgical nursing assessment and management of clinical problems. St. Louis : Mosby, Inc.

Lin, P.C., Lin, M.L., Huang, L.C., Hsu, H.C., \&

Lin, C.C. (2011). Music therapy for patients receiving spine surgery. Journal of Clinical Nursing, 20, 960 - 968.
Merskey, H., \& Bogduk, N. (1994).

Classification of chronic pain, ( $2^{\text {nd }}$ ed). Seattle: IASP Press

Onieva-Zavra, M.D., Casto Sanchez, A.M., Mataran-Penarrocha, G.A., \& MorenoLorenzo, C. (2013). Effec of music as nursing intervention for people diagnosed with Fibromyalgia. Pain Management Nursing. 14 (2), e39-46

Ozer, N., Karaman Ozlu, Z., Arslan, S., \& Gunes, N. (2010). Effect of music on postoperative pain and physiologic parameters of patient after open heart surgery. Pain Management Nursing, 14 (1), 20 - 28

Potter, P.A., \& Perry, A.G. (2011). Fundamentals of Nursing. 6 th edition. St. Louis, MO: Mosby.

Radcliffe, J.A., \& Porterfield, S. (2018). Music therapy and post-operative pain. Retrieved from http://purl.flvc.org/fsu/fd/FSU_libsubv1_s cholarship_submission_1524522463_c06 dae 03

Schneider, M.A. (2018). The Effect of Listening to music on postoperative pain in adult orthopedic patients. Journal of Holistic Nursing. 36 (I), 23 - 32.

Smeltzer, S. C., \& Bare, B. G. (2010). Brunner \& Suddarth's Textbook of Medical Surgical Nursing. Philadelphia : Lippincott. 